\title{
Toxicity and Benefits of Urban Stabilized Sludge Intended for Agriculture Use
}

\author{
ION-VIOREL PATROESCU, STEFANIA GHEORGHE* , IOANA ALEXANDRA IONESCU, \\ IONUT CRISTEA, IRINA EUGENIA LUCACIU, ROXANA-ELENA SCUTARIU, \\ MIHAI NITA-LAZAR
}

National Research and Development Institute for Industrial Ecology - ECOIND, 71-73 Drumul Podu Dambovitei Str., 060652, Bucharest, Romania

Abstract: Sludge reuse is one of the main challenges of waste management and an action with environmentally consequences that must be kept under control. The progress of civilization leaded to the globally increase of sludge production. WWTPs treatment technologies, sludge disposal/recovery and also quality control and toxicological involvements became parts of strategical actions at international level. The main disposal strategies for sludge management include agriculture or landscaping purposes, or final disposal. The accepted international policy is sludge application as organic fertilizer in agriculture. In this context, the research paper presents laboratory data used in decisional actions for the sludge land disposal. The study covers physical and chemical characterization of sludge resulted from Focsani WWTP, agriculture soil collected from around of Focsani WWTP and their leachates in compliance with national norms. In addition, the toxic effects on soil organisms (plants) were evaluated. Generally, soil and sludge quality meet the normed criteria for minimizing the potential impact on the environment. The leachate experiments showed the nonhazardous character on the soil properties of groundwater, the predicted impact being insignificant for the tested sludge / soil chemical composition. Ecotoxicological assessment of stabilized sludge showed inhibitory effects in the range of $25 \%$ to $100 \%$ on seed germination and root growth of plants Sorghum sacharatum, Sinapis alba and Lepidium sativum. In the range of $1 \%$ or $5 \%$ no significant inhibitory effect of sludge on plants growth was observed. Sorghum sacharatum showed the best growth, but there were no relevant differences between species. A saftey dose of $5 \%$ sludge mixed with agriculture soil (250 tonnes per hectare) was established. A monitoring program of sludge / soil quality and also ecotoxic evaluation was recomanded for the saftey of crops growth and health of living organisms including humans.

Keywords: sludge, agriculture, phytotoxicity

\section{Introduction}

Sewage sludge management is one of the main problem of the water regime in the human communities. Sludge production is a continuous process, due to the urban areas strong development and the recent progress of civilization, which involves finding flexible and sustainable solutions for sludge evaluation, recycling or recovery of organic substances. Although sludge is classified as waste according to the waste management, the accepted international policy is to be use as organic fertilizer or as energy source recovered by combustion [1].

In the context of a sustainable development, it is necessary to improve the techniques adopted for the elimination and /or recovery of the urban wastewater sludge in accordance with each country specific legislative and economic requirements. Sludge production in UE is in a continue increase, the amount of sewage sludge produced increased by more than $50 \%$, from 6.5 million tons of dry matter (DM) in 1992 to 10.9 million tons in 2015 [2]. According to the European Union's and other countries' demographic projections, the total sludge production in the Union in 2020 increased to 13 million tons DM [3].

*email: stefania.gheorghe@incd.ecoind.ro 
The total sludge production was more than 283 thousand tones in 2017 in Romania with $15 \%$ more than 2016. At national level an increase of sludge disposal in agriculture use, about 35 thousand tons in 2018, double compared to 2017, was observed [2].

The agricultural use is an approved measure by the EU as an appropriate environmental practice. Statistical data show that in EU $>35 \%$ of the total sludge production resulting from wastewater treatment is applied in agriculture and this rises up to $>50 \%$ in Spain, Irelander, Germany, Italy or Denmark [4]. The proportions vary between countries, according to the WWTPs technologies, sludge composition, soil characteristics, agriculture type and other factors [5]. The reuse of sludge in agriculture could have benefic effects especially there where the soil is infertile or it could determinate environmental concerns related to pollutant accumulation [6].

In EU the sludge reuse in agriculture is conditioned by the Urban Treatment Directive 91/271/EEC and Directive 86/287/EEC in order to minimize the potential impact on the environment and human health $[7,8]$. Sludge can improve the soil fertility trough the nutrients $(\mathrm{N}, \mathrm{P}, \mathrm{Na}, \mathrm{K}, \mathrm{Ca}, \mathrm{Mg})$ and organic matter inputs. However, there are some issues related to the content of toxic substances such as heavy metals $(\mathrm{Cd}, \mathrm{Ni}, \mathrm{Cu}, \mathrm{Pb}, \mathrm{Zn})$, hazardous organic chemicals (aromatic hydrocarbons, amines, nitrosamines, pesticides, pharmaceuticals, detergents, hormone disruptors, biocide or surfactants), that can accumulate in the soil layer and can affect the soil organism's ecosystem, plant productivity, soil structure. Due to the bioaccumulation process, these compounds could have potential risk on human health $[4,9,10]$. Other concerns of land sludge reuse are related to the pathogenic microorganisms that could contaminate the vegetables and then be transmitted to humans [11].

Sludge impact used as fertilizer on environment compartment (soil), could be evaluated through chemical characterizations, leachates tests or using living soil organisms such as plants or other invertebrate species. The ecotoxicological tests applied for sludge evaluations reveled a variety of results in relation to the organism's sensitivity and also a series of interferences concerning the observed effects [12]. The phytotoxic tests are manly used to obtain a global toxicity response to the complex matrices of sludge on plants [13]. The effects on plants result as a common action of more factors such as: presence of dangerous pollutants (heavy metals, PAHs, PCBs), pollutants bioavailability, organic matter content, soil $p \mathrm{H}$, soil structure, climatic conditions, humidity, nutrients balance, microbial charge, etc. [9, 14]. The metabolites resulted after organic compounds biodegradation could contribute to the toxicity degree due to their bioavailability and mobility. These compounds are not monitored and could be easily migrate from soil in groundwater or in plants [15]. The agriculture sludge use and the potential risk depends on the sludge composition. From this reason, numerous researches are focused on sludge quality and their sustainable reuse.

The sludge reuse is conditioned by the sludge treatment complexity. The treated sludge is defined as the product that has been subjected to a "biological, chemical, thermal, long-term storage or any other appropriate process to reduce its reactivity and health risks when is case of use" [8]. Before use, the sludge is thickened, anaerobic or aerobic fermented, conditioned and dehydrated.

The paper aim is to present laboratory data regarding the quality of a municipal treated sludge resulted from Focsani WWTP with agriculture purpose. The environmental impact will be presented following the toxic effects on soil organisms (plants). The study covers physical and chemical analyzes for sludge and soil, leachates characterizations in compliance with national norms and ecotoxic level.

\section{Materials and methods}

\subsection{Materials}

\subsubsection{Soil}

The agriculture soil used in the experimental study (for leaching test or sludge dilution in phytoxicity tests) was collected from $10-20 \mathrm{~cm}$ depth, from around of Focsani WWTP $\left(45^{\circ} 41^{\prime} 4.90 " \mathrm{~N}\right.$ $\left.27^{\circ} 13^{\prime} 12.07 " \mathrm{E}\right)$. Using direct observation and comparing to Munsell color determinant, the soil was 7.5 YR 4/1 dark grey with a sandy and loam texture, glomerular structure, high porosity, and reduced 
humidity. The morphological properties observations of the soil corespond to a compact cernoziom soil.

For toxicity control tests OECD soil (85\% sand, $10 \%$ kaoline and $5 \%$ peat) provided by MicroBiotests Belgium (batch no. OERS050419) was used as reference according to SR EN ISO 11269-1 methodology [16].

\subsubsection{Sludge}

The sludge used in the experimental study was collected from Focsani city $\left(45^{\circ} 41^{\prime} 49^{\prime \prime} \mathrm{N}\right.$ $\left.27^{\circ} 11^{\prime} 12^{\prime \prime} \mathrm{E}\right)$ wastewater treatment plant located. Focsani city has about 80000 inhabitants and the principal anthropogenic activities are textile confections, wine and food production. The sludge was anaerobically stabilized, dehydrated and dried for 2 months in special greenhouses in the region specific climatic conditions.

\subsubsection{Biological material}

The phytotoxic tests were performed using selected plants: Sorghum saccharatum - sorghum, monocotyledonate (SOS 151217); Lepidium sativum - cress, dicotyledonate, aromatic or medicinal plant (LES 121017); and Sinapis alba - mustard, dicotyledonate, aromatic plant or condiment (SIA 230218) provided by MicroBioTests Belgium - Phytotoxkit microbiotest (PT019).

\subsubsection{Reagents}

All the used reagents were analytical grade. For the relevance of phytotoxic tests, boric acid was used as reference pollutant.

\subsection{Methods}

\subsubsection{Soil and sludge analytical characterization}

The soil and sludge quantitative determinations of more than 30 chemical parameters were performed using standardized methods.

Total nitrogen $(\mathrm{N})$ and total organic carbon (TOC) determination were performed according to the standards SR EN 16168:2013 and SR EN 15936:2013-method B [17, 18]. These methods are based on combustion at $900^{\circ} \mathrm{C}$ of a known sample amount followed by reduction, capture, chromatographic separation and quantitative determination of gaseous products using a THERMOFISHER analyzer, type FLASH-EA1112 CHNS.

The AOX indicator was determined by applying the standard SR EN 16166: 2013 [19]. The method is based on the adsorption of the halogenated organic compounds from the dried solid sample on activated carbon. Inorganic halides are eluted by stirring with nitric acid solution, while organic halides are adsorbed on the activated carbon, the mixture being filtered using quartz frites. Halogenated organic compounds are determined by combustion at $1000^{\circ} \mathrm{C}$ followed by microculometric titration of the resulting gases. The result is expressed in mass concentration of chloride ions.

PAH's analytical method, ISO 13859:2014 (E), is based on the selective extraction of compounds from the solid sample, after lyophilization, in acetone and petroleum ether [20]. The obtained extract is subjected to purification on aluminum oxide after which the evaporation and exchange of the solvent is carried out with $1 \mathrm{ml}$ acetonitrile. Quantitative determination was done on an HPLC Ultimate 3000 (Thermo) coupled with a fluorescence detector by the external standard method.

Polychlorinated biphenyls (PCB) determination was performed according to the standard SR EN 16167:2013 [21]. This method is based on PCB's extraction from sludge in organic solvent (hexane, acetone) followed by purification of aluminum oxide (basic or neutral) in order to eliminate the interference. The extracts are concentrated by evaporation to a final volume of $1 \mathrm{ml}$. The analytes are separated with an Agilent HP-5MS capillary column coated with 5\% phenyl and 95\% dimethylsiloxane and quantified by gas chromatograph with ECD detector. PCB compounds were 
quantified using the internal standard method.

Elemental analysis was performed according to the standard SR EN 15309/2007 [22]. The samples were dried at $105^{\circ} \mathrm{C}$, then calcined at $550^{\circ} \mathrm{C}$. The calcined material was wet and passed through a sieve for particles $<0.5 \mathrm{~mm}$. Approximately $2 \mathrm{~g}$ of the sample was introduced into polypropylene cups (diameter $32 \mathrm{~mm}$ ) equipped with transparent Prolene ${ }^{\circledR}$ film $(4 \mu \mathrm{m})$, after which they were analyzed using ED-XRF Rigaku CG equipment (Rigaku, Japan). The obtained were related to the dried samples.

\subsubsection{Leaching tests}

Considering that both sludge and soil must comply with the quality conditions imposed by national legislation, leaching tests were performed. These tests simulate the percolation phenomena by the meteoric waters of the sludge deposited on agricultural soils and can estimate the harmful potential and the impact on the soil and groundwater. In order to highlight the effects produced by sludge on the soil, mixtures of the sludge dose commonly applied in agriculture (50 tons / hectare) were made.

The mixtures were subjected to leaching tests according to SR EN 12457-2:2003 and the results were compared to waste acceptance criteria set by national Order no. $95 / 2005[23,24]$. The method is based on the direct contact of sludge / soil mixture with leachate (distillated water), in a ratio of 1:10 for $24 \mathrm{~h}$ and the separation of leachate for chemical analyses.

\subsubsection{Ecotoxicity tests}

The phytotoxicity tests were performed according to SR EN ISO 11269:2013 regarding the evaluation of pollutants effects on soil flora, part 1 - method for the measurement of inhibition of root growth [16]. The laboratory experiments supposed 3 days of direct sludge contact with the 3 different type of plants seeds (sorghum, white mustard and cress).

The toxicity on plants was performed in a thermostatically controlled incubator with built-in lights suitable for all Microbiotests Toxkits.

At the end of the incubation period the inhibition degree of seeds germination and early roots growth compared to the control were evaluated. The tests were applied in replicates to ensure statistically relevant results. The experimental data were expressed as means \pm standard deviation (SD).

The seed germination or root growth inhibition (I\%) were calculated, for each plant, according to the formula: $\mathrm{I} \%=\mathrm{A}-\mathrm{B} / \mathrm{A} \times 100$, where: $\mathrm{A}$ is the average of the germinated seeds or the length of the roots in the reference soil or the agricultural soil; B is the average of the germinated seeds or the length of the roots in the tested sludge. The inhibitory concentration for 50\% of tested organisms (IC50\%) was estimated for each plant species as regression of inhibitions (I\%) according to sludge concentrations.

The sludge sample was tested $100 \%$ and in different mixtures $(0 \%, 1 \%, 5 \%, 25 \%, 50 \%)$ with reference soil or agricultural soil. Two type of controls (without sludge enrichment) were used: 1) reference OECD soil and 2) agriculture soil.

The toxicity tests needed $1 \mathrm{~kg}$ of each sample (sludge / soil), dried, grounded and divided in $90 \mathrm{~cm}^{3}$ transparent test plates. Distilled water was used for moisture assurance. The needed water for saturation was about $35-70 \mathrm{~mL}$ at $90 \mathrm{~cm}^{3}$ according to the sample / control texture.

For each test plate and plant species, ten seeds were used. The seeds were placed over a black filter paper, at equal distances between them. The test was carried out at an incubation temperature of $25^{\circ} \mathrm{C}$, under dark conditions for 3 days in a thermostatically controlled incubator with built-in lights suitable for all Microbiotests Toxkits

The assessing of effects was made using test plates photographs realized at the end of test and analyzed with ImageJ Program for microscopy (LOCI, University of Wisconsin). 


\section{Results and discussions}

\subsection{Soil and sludge characteristics}

The chemical characterization of the soil was performed and the results are shown in the Table 1, which also includes the maximum allowable values for heavy metal concentrations in the soils where sludge is applied, according to the Order 344/708/2004 [25]. The soil parameters highlighted the following aspects: the $p \mathrm{H}$ value indicated that soil reaction is moderately alkaline, the moisture was low, the $\mathrm{C} / \mathrm{N}$ ratio indicate a very low fertility and the metal content showed higher values. The soil quality respect the legislative requirements [25].

According to Order 756/1997 regarding the assessment of environmental pollution [26], the agriculture soil corresponded mostly to sensitive soils (alert threshold). The nutrients concentrations are lower compared to the sludge. The agricultural soil was used in phytotoxicity tests as control and also as diluent of sludge samples.

Table 1. Soil chemical parameters

\begin{tabular}{|c|c|c|c|c|c|}
\hline Parameter & UM & $\begin{array}{c}\chi_{\text {mean }} * * \\
\text { (threshold } \\
\text { values } * * * \text { ) }\end{array}$ & Parameter & $\mathbf{U M}$ & $\begin{array}{c}\chi_{\text {mean }}^{* *} \\
\text { (threshold } \\
\text { values } * * * \text { ) }\end{array}$ \\
\hline Dry matter & $\%$ & 82.09 & Cadmium (Cd) & $\mathrm{mg} / \mathrm{kg}$ d.m. & $<2(3)$ \\
\hline $\mathrm{pH}$ & unit $\mathrm{pH}$ & 8.31 & Copper $(\mathrm{Cu})$ & $\mathrm{mg} / \mathrm{kg}$ d.m. & $59(100)$ \\
\hline $\begin{array}{l}\text { Total organic matter } \\
\text { (TOC) }\end{array}$ & $\%$ d.m.* & 1.71 & Nickel (Ni) & $\mathrm{mg} / \mathrm{kg}$ d.m. & $43(50)$ \\
\hline Total nitrogen $(\mathrm{N})$ & $\%$ d.m. & 0.24 & Lead $(\mathrm{Pb})$ & $\mathrm{mg} / \mathrm{kg}$ d.m. & $30(50)$ \\
\hline Total phosphorus $(\mathrm{P})$ & $\mathrm{mg} / \mathrm{kg}$ d.m. & 0.07 & Zinc (Zn) & $\mathrm{mg} / \mathrm{kg}$ d.m. & $117(300)$ \\
\hline Carbon/ Nitrogen & - & 7.12 & Mercury (Hg) & $\mathrm{mg} / \mathrm{kg}$ d.m. & $0.9(1)$ \\
\hline $\begin{array}{c}\text { Halogenated } \\
\text { organic } \\
\text { compounds }(\mathrm{AOX})\end{array}$ & $\mathrm{mg} / \mathrm{kg}$ d.m. & 60 & Chromium $(\mathrm{Cr})$ & $\mathrm{mg} / \mathrm{kg}$ d.m. & $44(100)$ \\
\hline $\begin{array}{l}\text { Polycyclic aromatic } \\
\text { hydrocarbons (PAH) }\end{array}$ & $\mathrm{mg} / \mathrm{kg}$ d.m. & 0.013 & Cobalt (Co) & $\mathrm{mg} / \mathrm{kg}$ d.m. & 129 \\
\hline $\begin{array}{l}\text { Polychlorinated } \\
\text { biphenyls ( PCB) }\end{array}$ & $\mathrm{mg} / \mathrm{kg}$ d.m. & $<0.01$ & Arsenic (As) & $\mathrm{mg} / \mathrm{kg}$ d.m. & 11 \\
\hline Sulfur (S) & $\mathrm{mg} / \mathrm{kg}$ d.m. & 890 & $\begin{array}{c}\text { Barium }(\mathrm{Ba}) \\
\text { Molybdenum (Mo) }\end{array}$ & $\begin{array}{l}\mathrm{mg} / \mathrm{kg} \text { d.m. } \\
\mathrm{mg} / \mathrm{kg} \text { d.m. }\end{array}$ & $\begin{array}{l}321 \\
<25\end{array}$ \\
\hline Chlorides $\left(\mathrm{Cl}^{-}\right)$ & $\mathrm{mg} / \mathrm{kg}$ d.m. & 176 & Selenium $(\mathrm{Se})$ & $\mathrm{mg} / \mathrm{kg}$ d.m. & 3 \\
\hline Sodium $(\mathrm{Na})$ & $\mathrm{mg} / \mathrm{kg}$ d.m. & 6,450 & Antimony (Sb) & $\mathrm{mg} / \mathrm{kg}$ d.m. & $<25$ \\
\hline Potassium $(\mathrm{K})$ & $\mathrm{mg} / \mathrm{kg}$ d.m. & 25,633 & Manganese (Mn) & $\mathrm{mg} / \mathrm{kg}$ d.m. & 1,072 \\
\hline Calcium (Ca) & $\mathrm{mg} / \mathrm{kg}$ d.m. & 23,868 & Aluminum (Al) & $\mathrm{mg} / \mathrm{kg}$ d.m. & 90,507 \\
\hline Magnesium (Mg) & $\mathrm{mg} / \mathrm{kg}$ d.m. & 11,931 & Titan (Ti) & $\mathrm{mg} / \mathrm{kg}$ d.m. & 4,455 \\
\hline Iron $(\mathrm{Fe})$ & $\mathrm{mg} / \mathrm{kg}$ d.m. & 40,546 & Silicium (Si) & $\mathrm{mg} / \mathrm{kg}$ d.m. & 267,513 \\
\hline
\end{tabular}

Two samples of sludge were characterized according to legislative norms applied for the sludge intended to be use in agriculture, Order no.344/708/2004 [25]. The characteristics of sludge are presented in Table 2, together with the maximum allowable concentrations of the quality parameters for sludge used in agriculture. The sludge presents a moisture of $56 \%$, a neutral $p \mathrm{H}$, a moderate organic content, contain essential nutrients for plants grow and development ( $\mathrm{N}, \mathrm{P}, \mathrm{Na}, \mathrm{K}, \mathrm{Ca}, \mathrm{Mg}, \mathrm{Fe}$, $\mathrm{Cu}, \mathrm{Zn}, \mathrm{Mo}, \mathrm{Se}, \mathrm{Mn}$ ), but also toxic heavy metals such as $\mathrm{Cd}, \mathrm{Pb}$ and $\mathrm{Cr}$. As or $\mathrm{Hg}$ were not identified. The metals are present as very soluble salts or in combinations strongly linked to the organic material present in the sludge. Specific organic pollutants such as AOX $(>100 \mathrm{mg} / \mathrm{kg} \mathrm{d.m.)} \mathrm{and} \mathrm{PAH}(<1 \mathrm{mg} / \mathrm{kg}$ d.m) were identified. All the parameters respect the Romanian law limits for the identification of potential hazards induced by the use of sludge when applied on these soils [25].

Contrary, the $\mathrm{N}, \mathrm{P}$ and $\mathrm{K}$ exceed the maximum concentrations recommended by the document „Elaboration of the national policy for the management of the sewage sludge. National sewage sludge management strategy. Part III, 2012 - table 2.4 General parameters and nutrients". In addition, sludge has metals such as $\mathrm{Zn}, \mathrm{Cu}, \mathrm{Ni}, \mathrm{Pb}, \mathrm{Cr}, \mathrm{Fe}$, and $\mathrm{Mn}$, whose concentrations are within the average or median values estimated by the mentioned document. Maximum values of $\mathrm{Cd}$, $\mathrm{Co}$ and $\mathrm{Se}$ are 
observed. The AOX concentration is within the average value, and the PAH concentration exceeds the maximum concentration.

According to literature data the $\mathrm{C} / \mathrm{N}$ ratio is low (5.53) compared with 7.9 - 8.2 [27] which favors the sludge mineralization. Also the $\mathrm{Na}$ and $\mathrm{S}$ are outside of range values, respectively $0.3-2.6 \mathrm{~g} / \mathrm{Kg}$ for $\mathrm{Na}$ or $11-17 \mathrm{~g} / \mathrm{Kg}$ for $\mathrm{S}[27,28]$. The macronutrients $(\mathrm{N}, \mathrm{P}, \mathrm{K}, \mathrm{Ca}, \mathrm{Mg}$ ), micronutrients $(\mathrm{Fe}, \mathrm{Zn}, \mathrm{Cu}$, $\mathrm{Mn}, \mathrm{Ni}$ and $\mathrm{Mo}$ ) and also toxic elements (Al, $\mathrm{Ba}, \mathrm{Cr}, \mathrm{Cd}, \mathrm{Pb}, \mathrm{Se}, \mathrm{As}, \mathrm{Hg}$ ) amounts are common with other sludge matrices [29]. The toxic metals have the following distribution: $\mathrm{Al}>\mathrm{Ba}>\mathrm{Cr}>\mathrm{Cd}>\mathrm{Se}>\mathrm{As}$, $\mathrm{Hg}$.

Table 2. Sludge chemical parameters

\begin{tabular}{|c|c|c|c|c|c|}
\hline Parameter & $\mathbf{U M}$ & $\begin{array}{c}\chi_{\text {mean }} * * \\
\text { (threshold values) }\end{array}$ & Parameter & UM & $\begin{array}{c}\chi_{\text {mean }} * * \\
\text { (threshold values) }\end{array}$ \\
\hline Dry matter & $\%$ & 44.08 & Cadmium (Cd) & mg/kg d.m. & $10(10) * * *$ \\
\hline Volatile matter & $\%$ d.m. ${ }^{*}$ & 49.44 & Copper $(\mathrm{Cu})$ & mg/kg d.m. & $183(500)$ \\
\hline $\mathrm{pH}$ & unit $\mathrm{pH}$ & 6.73 & Nickel (Ni) & $\mathrm{mg} / \mathrm{kg}$ d.m. & $34(100)$ \\
\hline $\begin{array}{l}\text { Total organic matter } \\
\text { (TOC) }\end{array}$ & $\%$ d.m. & 25.78 & Lead $(\mathrm{Pb})$ & mg/kg d.m. & 44 (300) \\
\hline Total nitrogen $(\mathrm{N})$ & $\%$ d.m. & 4.66 & Zinc $(\mathrm{Zn})$ & mg/kg d.m. & $763(2,000)$ \\
\hline $\begin{array}{c}\text { Total phosphorus }(\mathrm{P}) \\
\text { Halogenated }\end{array}$ & $\mathrm{mg} / \mathrm{kg}$ d.m. & 22,398 & Mercury (Hg) & $\mathrm{mg} / \mathrm{kg}$ d.m. & $<2(5)$ \\
\hline $\begin{array}{c}\text { organic } \\
\text { compounds }(\mathrm{AOX})\end{array}$ & mg/kg d.m. & $160(500)$ & Chromium $(\mathrm{Cr})$ & mg/kg d.m. & $100(500)$ \\
\hline $\begin{array}{l}\text { Polycyclic aromatic } \\
\text { hydrocarbons (PAH) }\end{array}$ & mg/kg d.m. & $0.54(5)$ & Cobalt (Co) & mg/kg d.m. & $47(50)$ \\
\hline $\begin{array}{c}\text { Polychlorinated } \\
\text { biphenyls ( PCB) }\end{array}$ & mg/kg d.m. & $<0.01(8)$ & Arsenic (As) & mg/kg d.m. & $<2(10)$ \\
\hline Sulfur (S) & mg/kg d.m. & 5157 & Barium (Ba) & mg/kg d.m. & 168 \\
\hline & & & Molybdenum (Mo) & $\mathrm{mg} / \mathrm{kg}$ d.m. & $<25$ \\
\hline Chlorides $\left(\mathrm{Cl}^{-}\right)$ & mg/kg d.m. & 678 & Selenium $(\mathrm{Se})$ & $\mathrm{mg} / \mathrm{kg}$ d.m. & 4 \\
\hline Sodium $(\mathrm{Na})$ & $\mathrm{mg} / \mathrm{kg}$ d.m. & 15,168 & Antimony (Sb) & $\mathrm{mg} / \mathrm{kg}$ d.m. & $<25$ \\
\hline Potassium (K) & mg/kg d.m. & 9,101 & Manganese (Mn) & mg/kg d.m. & 418 \\
\hline Calcium $(\mathrm{Ca})$ & $\mathrm{mg} / \mathrm{kg}$ d.m. & 44,644 & Aluminum (Al) & $\mathrm{mg} / \mathrm{kg}$ d.m. & 21,690 \\
\hline Magnesium (Mg) & $\mathrm{mg} / \mathrm{kg}$ d.m. & 8,494 & Titan (Ti) & $\mathrm{mg} / \mathrm{kg}$ d.m. & 1,850 \\
\hline $\operatorname{Iron}(\mathrm{Fe})$ & $\mathrm{mg} / \mathrm{kg}$ d.m. & 15,269 & Silicium (Si) & $\mathrm{mg} / \mathrm{kg}$ d.m. & 69,773 \\
\hline
\end{tabular}

*dry matter; ** mean of two samples; ***threshold values established by Order no.344/708/2004

\subsection{Leaching tests}

Table 3 presents the characteristics of the eluates obtained from mixing sludge with agriculture soil. The test aim was to highlight the polluting potential of organic and inorganic constituents from soil / sludge mixture, compared with the threshold values set by Order no. 95/2005 [24].

Table 3 Leachate characteristics

\begin{tabular}{|c|c|c|c|}
\hline Quality indicator & $\begin{array}{c}\chi_{\text {mean }}^{* *} \\
\text { (threshold values: inert, } \\
\text { harmless, dangerous) }\end{array}$ & Quality indicator & $\begin{array}{c}\chi_{\text {mean }} * * \\
\text { (threshold values: inert, harmless, } \\
\text { dangerous) }\end{array}$ \\
\hline $\mathrm{pH}$ & 7.38 & $\begin{array}{l}\text { Chromium total }(\mathrm{Cr}) \text {, } \\
\mathrm{mg} / \mathrm{kg} \text { d.m. }\end{array}$ & $3.6(0.5 ; 10 ; 70)$ \\
\hline Conductivity, $\mathrm{mS} / \mathrm{cm}$ & 151 & Cobalt (Co), mg/kg d.m. & 0.013 \\
\hline $\begin{array}{c}\text { Cadmium }(\mathrm{Cd}) \\
\text { mg/kg d.m.* }\end{array}$ & $0.15(0.04 ; 1 ; 5 * * *)$ & Arsenic (As), mg/kg d.m. & $0.19(0.5 ; 2 ; 25)$ \\
\hline Copper $(\mathrm{Cu}), \mathrm{mg} / \mathrm{kg}$ d.m. & $5(2 ; 50 ; 100)$ & $\begin{array}{c}\text { Manganese (Mn), } \\
\text { mg/kg d.m. }\end{array}$ & 3.1 \\
\hline Nickel (Ni), mg/kg d.m. & $5.1(0.4 ; 10 ; 40)$ & Sulfates $\left(\mathrm{SO}_{4}^{-}\right), \mathrm{mg} / \mathrm{kg}$ d.m. & $\begin{array}{c}195(1,000 ; 20,000 ; \\
50,000)\end{array}$ \\
\hline Lead $(\mathrm{Pb}), \mathrm{mg} / \mathrm{kg}$ d.m. & $1.8(0.5 ; 10 ; 50)$ & Chlorides $\left(\mathrm{Cl}^{-}\right), \mathrm{mg} / \mathrm{kg}$ d.m. & $105(800 ; 15,000 ; 25,000)$ \\
\hline Zinc (Zn), mg/kg d.m. & $1.2(4 ; 50 ; 200)$ & $\begin{array}{l}\text { Dissolved organic } \\
\text { carbon (DOC), }\end{array}$ & $123(500 ; 800 ; 1,000)$ \\
\hline $\operatorname{Mercury}(\mathrm{Hg}), \mathrm{mg} / \mathrm{kg}$ d.m. & $0.02(0.1 ; 0.02 ; 2)$ & $\mathrm{mg} / \mathrm{s}$ & \\
\hline
\end{tabular}

*dry matter; ** mean of two samples; $* * *$ threshold values: inert, harmless, dangerous class for leachates quality according to Order no. 95/2005 (Liquid / Solid =10 L/kg) [24] 
The leachate analyses revealed non-hazardous characteristics. The heavy metal content $(\mathrm{Cu}, \mathrm{Ni}, \mathrm{Pb}$, $\mathrm{Cr}, \mathrm{Cd}, \mathrm{As}$,) is harmless and due to small concentrations, estimated effects related to the translocation in the trophic chain in low. Other indicators such as $\mathrm{Zn}$, sulphates, chlorides and dissolved organic carbon (DOC) are in the inert class according to national legislation.

The nature of organic compounds from sludge is in relation with the amount of leaching constituents. The leaching of metals from mixture in water was reduced due to the texture, structure and compaction degree of soil that contribute to the limitation of pollutants transfer. The heavy metals solubility is managed by adsorption/ desorption, precipitation / dissolving and complexing reactions that affect the metal repartition between soil or liquid phases.

Regarding the essential nutrients $\mathrm{C}, \mathrm{N}$ and $\mathrm{P}$, an increase of their concentrations was observed. Additionally, the neutral $p \mathrm{H}$, practically improved the soil characteristics. Considering that the mixture soil/sludge has non-dangerous character in the leachate, it can be estimated that the impact of sludge application as fertilizer in agriculture is insignificant. The sludge use in agriculture represents the final step of treatment where the soil act as depuration system based on the capacity to process organic matter, to block the non-biodegradable pollutants and also based on the structural properties and climatic conditions. The soil treatment mechanisms refer to mechanic retention, biological oxidation, ions changes, chemical precipitation, adsorption/absorption and plant / organisms uptake.

Chemical components balance is very important, because both macro and micronutrients in high concentrations can lead to interactions with each other therefore increasing bioavailability and the toxic effects on organisms. The presence of toxic heavy metals is a major challenge in the decision of using or not sludge in agriculture. The level of toxic element concentrations in sludge, other properties related to the increase of bioavailability ( $p \mathrm{H}$, organic matter, etc.), the soil quality and the crop type (food or no-food) can also influence this decision.

Advantages and disadvantages of sludge processing technologies indicate that anaerobic digestion (that is our case) could generate biogas production, the materials could be use as fertilizer and the contaminants and pathogens are considerable reduced. The disadvantages refer to a slow degradation of organic matter, presence of $\mathrm{CO}_{2}$ and $\mathrm{H}_{2} \mathrm{~S}$ in generated gas and an excess moisture [29].

\subsection{Ecotoxicity tests}

Sludge toxicity was evaluated for three plants species: Lepidium sativum (LES), Sinapis alba (SIA) and Sorghum saccharatum (SOS) in order to establish its safety when used as fertilizer.

Figures 1 to 7 present the results regarding the inhibition of seeds germination and roots grow inhibition in two different condition, sludge mixed with reference soil and sludge mixed with agriculture soil.

\subsubsection{Seed germination}

The direct contact of seeds with the undiluted sludge inhibit the germination in the range of 70$100 \%$. The mixtures of sludge $(25 \%$ and $50 \%)$ with agriculture soil, as well the sludge mixed with reference soil in the same proportions showed inhibitions in the range of 0-60\% (Figure 1 and 2).

In the lowest concentrations ( 1 and 5\%), the sludge is no toxic for seed germination regardless the diluent, the rates of inhibitions being less than $10 \%$ compared to the controls. Both agricultural soil and reference soil recorded full germination - they did not determine effects on seed germination, being similar in behavior. The reference test conducted with boric acid reveled $100 \%$ germination indicating that the experiments were valid. 


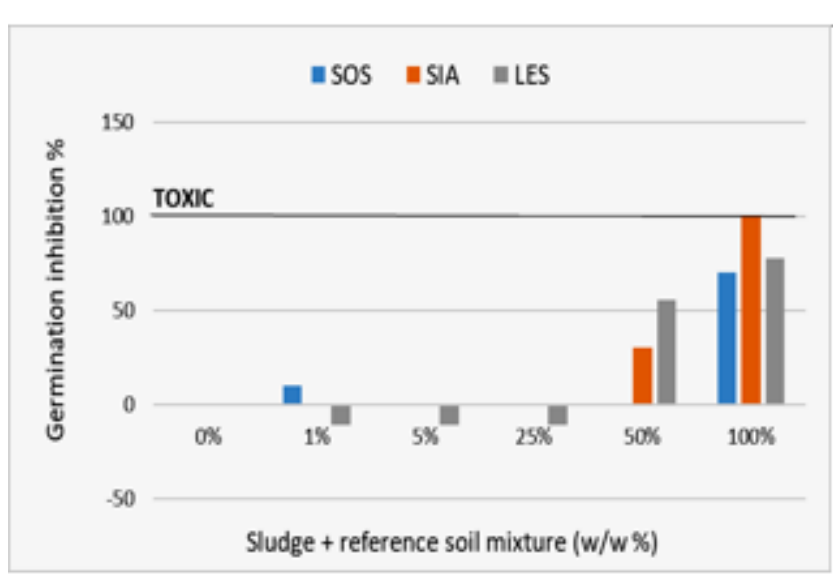

Figure 1. Inhibition of seed germination (sludge + reference soil)

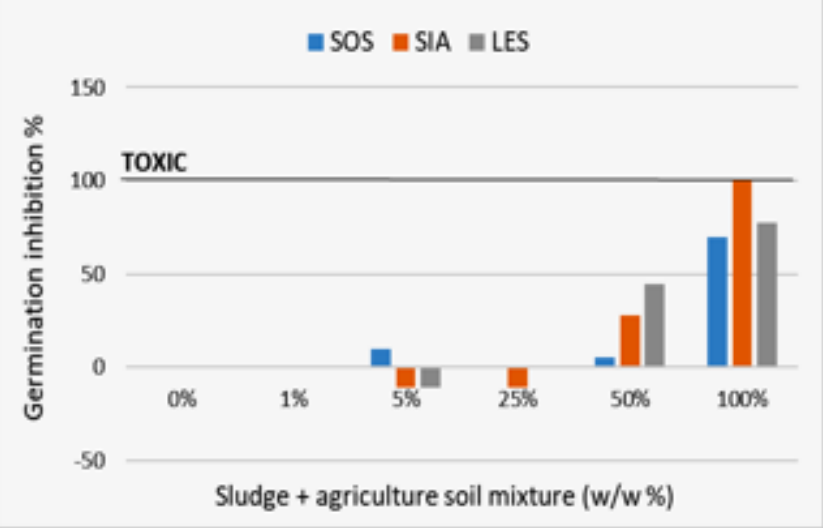

Figure 2. Inhibition of seed germination (sludge + agriculture soil)

\subsubsection{Roots grow inhibition}

Regarding the effects determined by sludge on the growth of plant roots, the mixtures in concentration of 50 and $100 \%$ inhibits roots formation, development and elongation. Sludge mixed $25 \%$ with agricultural soil or reference soil causes roots growth below of 5-10 mm for at less than 50\% of the planted seeds. Compared to the control the inhibition was about $100 \%$.

Similar results were also reported by other researches where a dose of $24 \%$ sewage sludge showed negative effects on seed germinations of Lepidium sativum. Levels of 20-100\% for roots growth inhibitions was noted [15].

No significant effects were observed in case of sludge mixtures 1 and $5 \%$ concentrations. There registered inhibition or stimulation effects of root length in the range of $1-30 \%$, being accepted in the controls values. Also, no significant differences regarding root growth between the two experiments (sludge / reference soil or sludge / agricultural soil) were observed. Both type of controls recorded similar increases in roots length (reference soil: $35.32 \mathrm{~mm}$ SOS, $52.12 \mathrm{~mm}$ SIA, $59.59 \mathrm{~mm}$ LES; agricultural soil: $35.04 \mathrm{~mm}$ SOS, $68.14 \mathrm{~mm}$ SIA and 50.21 mm LES) (Figure 3 and 4).

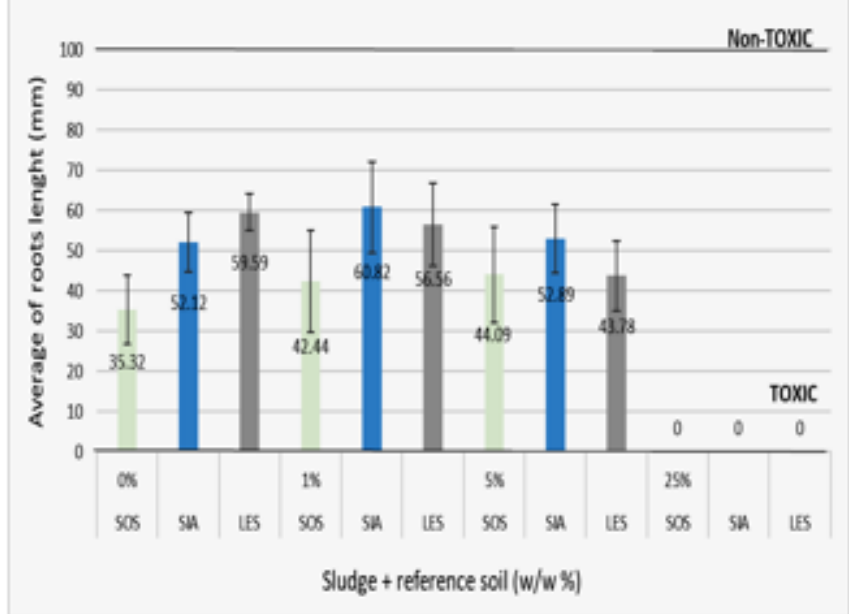

Figure 3. Roots length (test sludge + reference soil)

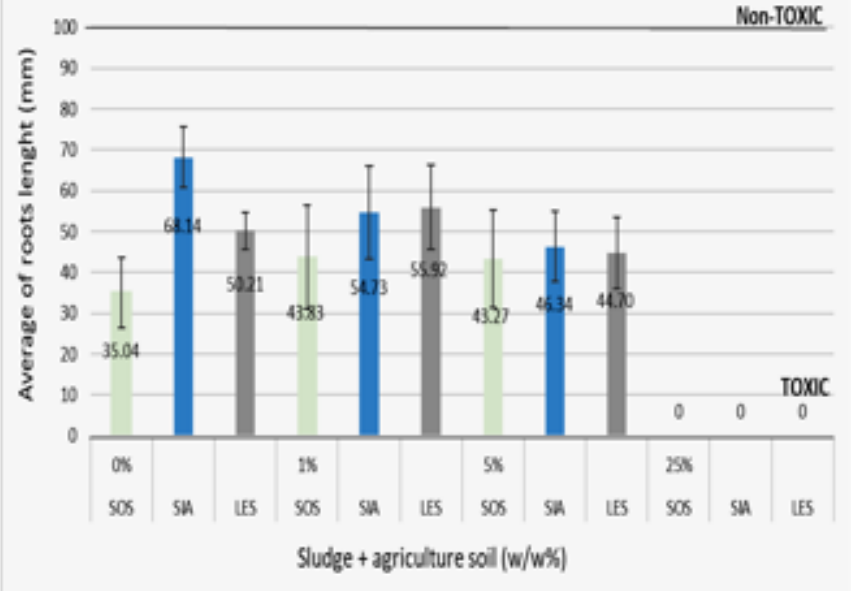

Figure 4. Roots length (test sludge + agriculture soil)

The mixture sludge / agriculture soil (1\% and 5\%) showed a slight stimulation (20\%) of roots in case of Sorghum sacharatum compared to the control (Figure 5 a, b, c, d). Sinapis alba (SIA) response indicate a $25-30 \%$ inhibition. A \pm 5 percentage (stimulation and inhibitions) effects were observed in 
case of Lepidium sativum. The effects magnitude depending on the sludge dose from the mixtures, being observed start to $5 \%$.

Oleszczuk P., 2007 and Carbonell et al., 2009 notice that the dose of sludge contribute to the increase of toxic effects on plants $[15,4]$.

Studies on sludge toxicity frequently reveled negative effects on tested organisms. The sludge application does not have significant effects on seed germinations but reduces the roots elongation, indicating that roots growth inhibition monitoring is the most sensitive method [30].

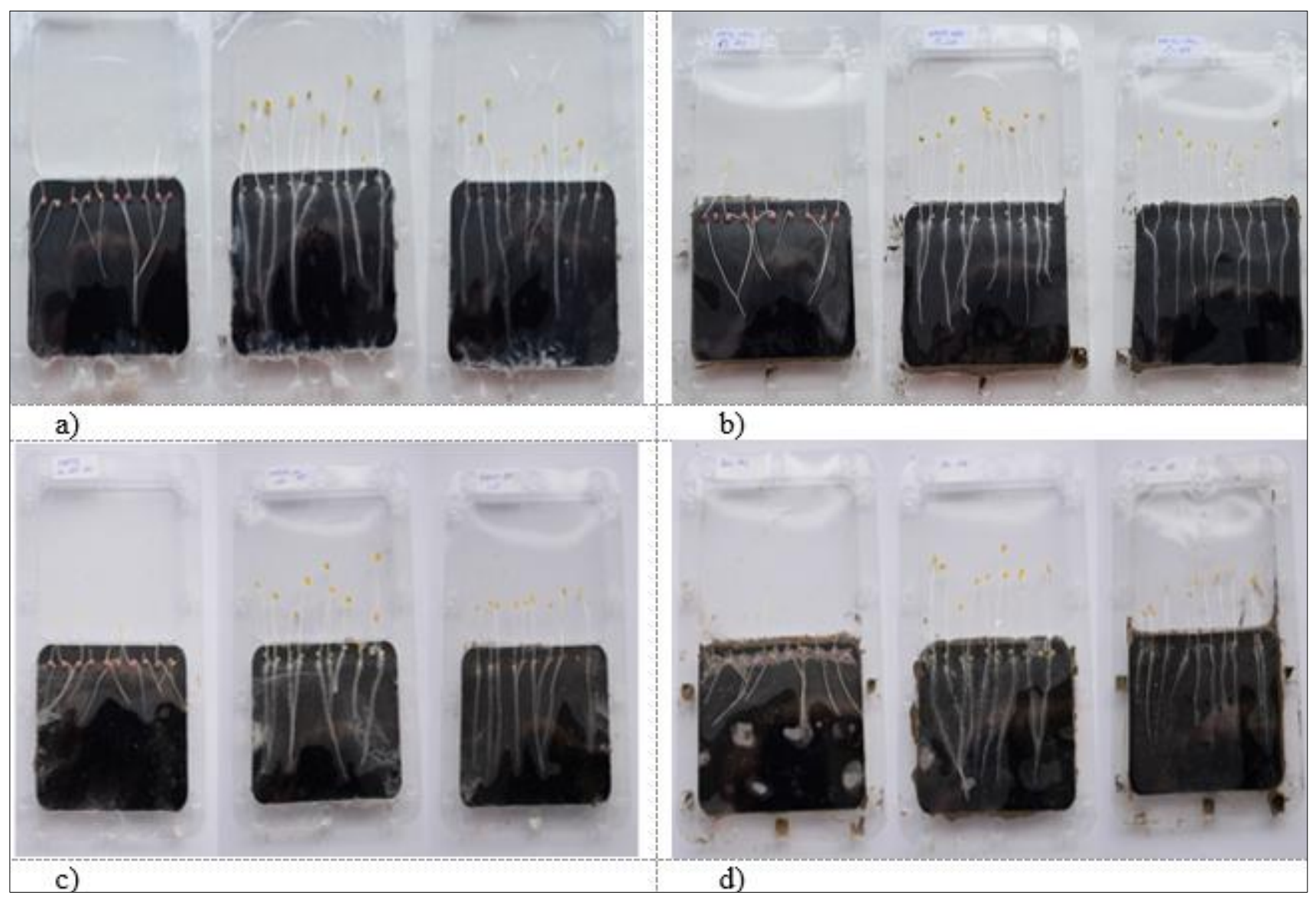

Figure 5. Seeds germination and roots growth of SOS, SIA and LES after 3 days of incubation:

a) test sludge $5 \%$ with reference soil; b) test sludge $5 \%$ with agriculture soil; c) control test - reference soil; d) control test - agriculture soil

Figures 6 and 7 show the graphical representation of roots growth inhibition (\%) of sludge in combination with agricultural soil or reference soil compared to the controls. Also the IC50\% estimation is presented. The IC50\% values determined for the tested plants exposed to the sludge / agricultural soil mixture were: SOS 44\%, SIA 37\%, LES $44 \%$ (Figure 6). The administration of the sludge on the agricultural soil is benefic for the plants growth in maximum proportions of 5\%, after this percentage toxic effect on the normal growth and plants development could be revealed.

Similar, the sludge diluted with reference soil caused root growth stimulation for Sorghum sacharatum (20\%) and also for Sinapis alba (10\%). Insignificant inhibition (5-25\%) for Lepidium sativum was revealed. The IC50\% values determined for the tested plants exposed to sludge - reference soil were: SOS 36\%, SIA 31\%, LES 24\% (Figure 7). The toxicity effects increase compared to those shown in the case of sludge mixed with agricultural soil. This finding indicates that the use of sludge in combination with poorer soil nutrients may have inhibitory effects on normal growth and plants development. The phytotoxic study showed that the application, in appropriate concentrations of dehydrated urban sludge in agriculture as soil fertilizer could stimulate plants development. 
The phytotoxic results for the sludge doze $1 \%$ are in correlation with leachates test performed for 50 tons / hectare. The non-toxic effects are maintained to 250 tons per hectare for an agriculture soil with the presented qualities. Moreover, the leachates tests showed that dangerous pollutants (especially the heavy metals) are found in small concentrations in leachate whiteout potential risk on organisms.

Many studies related that the use of sewage sludge as fertilizer increased the productivity of rice, wheat or corn crops [29]. Landfill studies with different varieties of Sorghum sacharatum revealed that the use of sludge ( $40 \mathrm{mg} \mathrm{DM} \mathrm{ha}{ }^{-1}$ ) as fertilizer increase the biomass production with a high energy value. They accumulated $\mathrm{N}$ and $\mathrm{Cd}, \mathrm{Zn}, \mathrm{Cu}, \mathrm{Ni}$ in high and medium levels and $\mathrm{K}, \mathrm{P}, \mathrm{Cr}, \mathrm{Fe}$ in small concentrations. In addition, the enzymatic, physical and chemical composition of soil were strongly improved [31].

Other studies suggest that an application rate of sludge for about 120 tons' dry matter per hectare in a soil microcosm (composed from plants and earthworms) could induce various effects such as a differentiated bioaccumulation behavior, inhibition of seed germinations in case of some plants (Brassica rapa), increase of biomass for other (Triticum aestivum and Vicia sativa), high bioaccumulation factor in earthworms for $\mathrm{Cd}$ and $\mathrm{Hg}$ and changes in biological activity of soil [4].

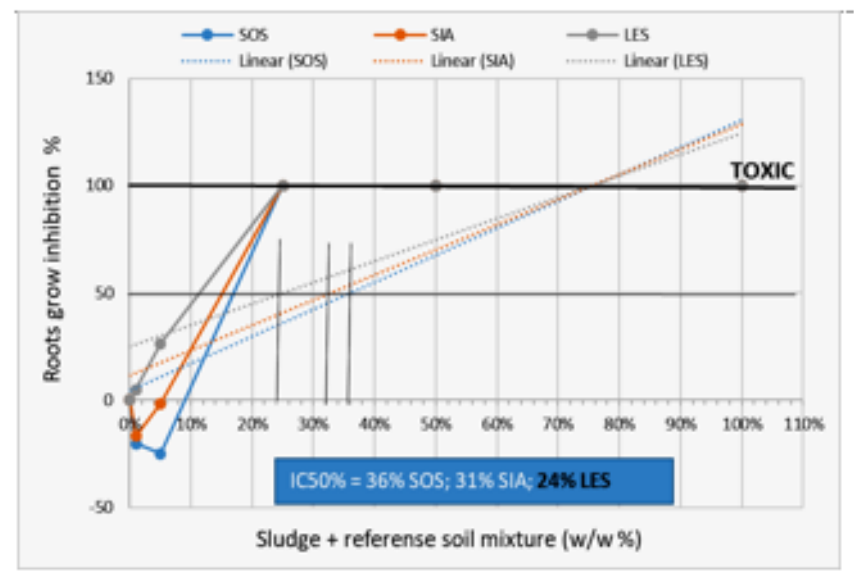

Figure 7. Roots grow inhibition / IC50\% estimation (test sludge + agriculture soil)

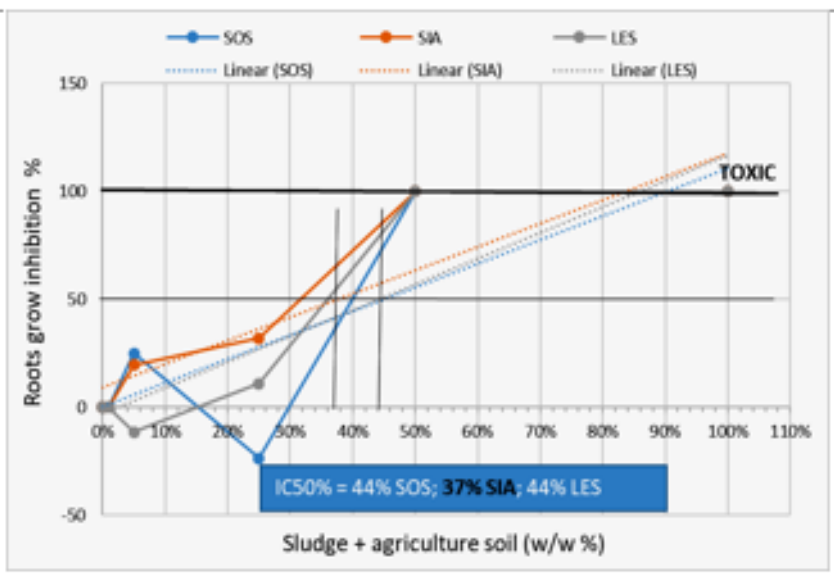

Figure 7. Roots grow inhibition / IC50\% estimation (test sludge + agriculture soil)

The control tests registered $100 \%$ germination for all three species plants. The minimum root length average in the control test with reference soil was $>30 \mathrm{~mm}$ for each plant species tested, after 3 days of incubation (Figure 5c, d). The tests also were validated using boric acid as reference substance. Toxicity values, respectively root growth inhibition for $250 \mathrm{mg} / \mathrm{kg}$ soil was within acceptable limits: Lepidium sativum 28-62\%, Sinapis alba 22-65\% and Sorghum saccharatum $9-52 \%$, according to the International Scheme of Interlaboratory Comparisons of the Phytotoxkit test.

Concerning that national legislation, Order no.344/708/2004 [25] specified for using of sludge in agriculture threshold values much lower that international legislation, Directive 86/287/EEC [8], the quality of this type of sludge's after treatment technologies is considerable improved and also the effects on environmental compartments it is expected to be reduced. Contrary, the phytotoxic tests classified the sludge (in 25 - 100\% doses) highly ecotoxic. Even though the sludge chemical indicators are in the normed threshold values, the presence of some critical pollutants (such as heavy metals, PCBs or PAHs) could have toxic effects on plants. For this reason, the scientific community recommended the sludge characterization using both physical and chemical analyses and bioassay tests [32]. 
Some studies showed that stabilized sludge, as is the case of Focsani sludge, are less toxic compared to other differently treated sludge. In addition, it is known that the sludge chemical structure is variable and as result their toxicity, in this context periodically assessments are required.

The laboratory biotesting of sludge can indicate only the short-term effects (in our case for 3 days), but the long term effects may vary do to modifications in the chemical and microbial composition.

A main problem in the use of sludge in agriculture remains the metal bioaccumulation that is a long-term effect. Many studies noted the bioaccumulation of metals in food plants when the sludge is used as fertilizer. The highest concentration of heavy metals was localized in roots and could also transfer in the plant aerial parts (leaves or fruits) [1].

Therefore, the plant capacity to hyper accumulate or not the metals play a very important roll [33]. One of the ways to avoid the environmental consequences related to pollutants bioaccumulation is the periodically monitoring of sludge and soil quality, reducing application frequency of sludge when it's not needed and identifying the most properly crops, regardless of the economic advantages.

\section{Conclusions}

The use of urban sludge in agriculture is one of the sustainable management options, being a measure approved by the EU as the best environmental practice. Given that the specific legislation regarding the quality of sludge and soils must meet certain requirements and the use of the sludge is controlled and monitored, the premises for minimizing the potential impact on the environment and human health are created.

The study showed the quality of stabilized sludge (from urban Focsani WWTP, Romania) and their toxicity or benefic effects if used in agriculture. The activities covered physical and chemical analyzes of the two implicated parts (sludge and soil), leachates characterizations, in compliance with national legislation and sludge ecotoxicological evaluation using plants. The research results have shown that the leachate of sludge mixed with agriculture soil have a non-hazardous character. The use of the tested sludge on the analyzed soil, even if it leads to the mobility of some small amounts of pollutants, do not generate negative effects on the land surfaces on which is deposited and also on the groundwater in the respective areas, the predicted impact being insignificant. The effects of sludge application as fertilizer, taking all the necessary measures to respect the quality, will be manifested in the short to medium term, depending on the nature of chemical matrices present in the sludge, the depuration mechanisms that take place at the soil level and also the climatic conditions.

Ecotoxicological evaluation of stabilized sludge intended to be use as fertilizer showed that in the range concentrations of 25 to $100 \%$ has inhibitory effects on seed germination and root growth of terrestrial plants: Sorghum sacharatum, Sinapis alba and Lepidium sativum. In small concentrations (1 or $5 \%$ ), the sludge mixed in soil does not cause significant inhibitory effects on the germination or roots growth of the plants tested. There are both stimulation and inhibition effects on root growth in the 1-30\% range that fulfil the control limits and in the acceptability criteria of the method.

Sorghum sacharatum showed the best growth compared to Sinapis alba and Lepidium sativum, but the differences between the species are not significant.

The use of stabilized sludge in combination with agricultural soil $(5 \%)$ demonstrated no toxic effects, and contrary, it can be beneficial for the growth and development of terrestrial plants. It is not recommended to exceed this dose or frequent application on the same soil, because toxic effects or bioaccumulation metallic elements in plants may occur.

The tested sludge can be used in agriculture on soils of normal quality according to the national legislation. It is recommended the application as a fertilizer in a proportion of maximum of $5 \%$ respectively about 250 tonnes per hectare. It is verry important to respecte the legislaton and also to perform periodic monitoring of the physical-chemical quality (with emphasis on the metallic elements and $\mathrm{PAH}$ ) of the soil on which it is applied. Moreover, monitoring the vegetation quality (especially if it is used for human or animal consumption) is recommended in order to avoid the uptake of bioaccumulative elements in the food chain. 
The main positive effect on the environment generated by the application of the sludge on agricultural lands is its valorization, in the context of the circular economy. Moreover, by sludge valorization, the amount of chemical fertilizers used today will be reduced, thus diminishing the energy consumption for their production.

Acknowledgments. This work was realized with the support of Operational Programme Competitiveness 2014-2020, Contract no. 55/05.09.2016, Project ID P_40_300, SMIS 105581, Subsidiary Contact no. 6538/27.04.2018.

\section{References}

1.ELMI, A., AL-KHALDY, A., ALOLAYAN, M., Sewage sludge land application: Balancing act between agronomic benefits and environmental concerns, J. Clean. Prod., 20, 2020, 119512. https://doi.org/10.1016/j.jclepro.2019.119512.

2.***EUROSTAT (2020) Environment database.

https://ec.europa.eu/eurostat/databrowser/view/ten00030/default/table?lang=en. (accessed 01 April 2020).

3.***UN DESA, Union Nation, Department of Economic and Social Affairs, Statistics News, July, 2014.

4.CARBONELL, G., GÓMEZ, J.P., BABÍN, M.M., FERNÁNDEZ, C., ALONSO, E., TARAZONA, J.V., Sewage sludge applied to agricultural soil: Ecotoxicological effects on representative soil organisms, Ecotoxicol. Environ. Saf., 72(4), 2009, 1309-1319.

https://doi.org/10.1016/j.ecoenv.2009.01.007.

5.***Environmental, economic and social impacts of the use of sewage sludge on land Final Report Part III: Project Interim Reports, 2010, prepared by Milieu Ltd, WRc and RPA for the European Commission, DG Environment under Study Contract DG ENV.G.4/ETU/2008/0076r.

https://ec.europa.eu/environment/archives/waste/sludge/pdf/part_iii_report.pdf.

6.PAY, D., MANZOOR, Q., DENNIS, W., Wastewater economic asset in an urbanizing world, Springer Dordrecht Heidelberg New York London, 2015, DOI 10.1007/978-94-017-9545-6.

7.***Directive 91/271/EEC, COUNCIL DIRECTIVE of 21 May 1991 concerning urban waste water treatment.

8.***Directive 86/287/EEC, COUNCIL DIRECTIVE of 12 June 1986 on the protection of the environment, and in particular of the soil, when sewage sludge is used in agriculture.

9.FUENTES, A., LLORENCS, M., SAEZ, J., AGUILAR, I., PEREZ-MARIN, A.B., ORTUNO, J.O., MESEGUER, V.F., Ecotoxicity, phytotoxicity and extractability of heavy metals from different stabilized sewage sludge, Environ. Pollut., 143(2), 2006, 355-360.

https://doi.org/10.1016/j.envpol.2005.11.035.

10.MITRU, D., NECHIFOR, G., GHEORGHE, S., BANCIU, A.R., IONESCU, L., STOICA, C., IONICA D.L., LUCACIU I.E., Removal and Effects of Surfactants in Activated Sludge System, Rev. Chim., 71(1), 2020, 100-106.

11.LOPEZ, A., RODRIGUEZ-CHUECA, J., MOSTEO, R., GOMEZ, J., Microbial quality of sewage sludge after digestion treatment: A pilot scale case of study, J. Clean. Prod., 254, 2020, 120101. https://doi.org/10.1016/j.jclepro.2020.120101

12.COORS, A., RICHTER, E., LORENZ, P., RÖMBKE, J., GIANICO, A., Ecotoxicity of sewage sludge, in Effective sewage sludge management edited by Giuseppe Mininni, Consiglio Nazionale delle Ricerche QUADERNI de "La Ricerca Scientifica", Roma 2013.

13.GHEORGHE, S., VASILE, GG., STOICA, C., NITA -LAZAR, M., LUCACIU, I., BANCIU, A., Phytotoxicity Tests Applied on Sewage Sludge Resulted from Urban Wastewater Treatment Plants, Rev. Chim., 67(8), 2016., 1469-1473. 
14.PUIU, D., POPESCU, M., NICULESCU, M., PASCU, F.L., GALAON, T., POSTOLACHE, C., Mobility of Some High Persistent Organochlorine Compounds from Soil to Mentha Piperita, Rev. Chim., 70(1), 2019, 278-282.

15.OLESZCZUK, P., The toxicity of compost from sewage sludge evaluated by the direct contact tests phytotoxkit and ostracodtoxkit, Waste Manage., 28(9), 2008, 1645 - 1653.

https://doi.org/10.1016/j.wasman.2007.06.016.

16.***ISO 11269-1:2012, Soil quality - Determination of the effects of pollutants on soil flora - Part 1: Method for the measurement of inhibition of root growth.

17.***SR EN 16168:2013 - Sludge, treated biowaste and soil - Determination of total nitrogen using dry combustion method.

18.***SR EN 15936:2013 - Sludge, treated biowaste and soil - Determination of total organic carbon (TOC) using dry combustion.

19.***SR EN 16166: 2013 - Sludge, treated bio-waste and soil. Determination of absorbable halogenated organic components.

20.***ISO 13859: 2014 (E) - Soil quality - Determination of polycyclic aromatic hydrocarbons by gas chromatography (GC) and high-performance liquid chromatography (HPLC).

21.***SR EN 16167:2013 - Sludge, treated biowaste and soil. Determination of polychlorinated biphenyls (PCB) by gas chromatography with mass selective detection (GC-MS) and gas chromatography with electron-capture detection (GC-ECD).

22.***SR EN 15309/2007 - Characterization of waste and soil. Determination of elemental composition by X-ray fluorescence.

24.***SR EN 12457-2:2003, Characterization of waste - leaching - compliance test for leaching of granular waste materials and sludge's - one stage batch test at a liquid to solid ratio of $101 / \mathrm{kg}$ for materials with particle size below $4 \mathrm{~mm}$ (without or with size reduction).

25 .***Order no.95/12 February 2005, regarding establishing of the acceptance criteria and preliminary procedures for storage of accepting waste and the national list of accepted wastes in each landfill class [in Romanian].

26.***Order no. 344/708/2004 regarding establishing the technical norms for environmental protection, especially of soils, when sewage sludge is used in agriculture [in Romanian].

27.***Order no.756/3 November 1997 regarding approval of the Regulation on environmental pollution assessment [in Romanian].

28.ARIF, M.S., RIAZ, M., SHAHZAD, S.M., YASMEEN, T., ASHRAF, M., SIDDIQUE, M., MUBARIK, M.S., BRAGAZZA, L., BUTTLER, A., Fresh and composted industrial sludge restore soil functions in surface soil of degraded agricultural land. Sci. Total Environ., 619-620, 2018, 517527. https://doi.org/10.1016/j.scitotenv.2017.11.143.

29.***CETESB (Environmental Company of the State of Sao Paulo), 2009. Physical-chemical, Microbiological, Parasitological and Ecotoxicological Characterization of Sludge from Sewage Treatment Plants in Sao Paulo. Technology Directorate, Sao Paulo, Brazil.

30.NASCIMENTO, A.L., SOUZA, A.J., OLIVEIRA, F.C., COSCIONE, A.R., VIANA, D.G., REGITANO, J.B., Chemical attributes of sewage sludges: Relationships to sources and treatments, and implications for sludge usage in agriculture, J. Clean. Prod., 258, 2020, 120746.

https://doi.org/10.1016/j.jclepro.2020.120746.

31.WONG, J.W.C., LI, K., SU, M., FANG, D.C., Toxicity evaluation of sewage sludge in Hong Kong, Environ. Int., 27, 2001, 373-380.

32.KOŁODZIEJ, B., ANTONKIEWICZ, J., STACHYRA, M., BIELINSKA, E.J., WISNIEWSKIA, J., LUCHOWSKA, K., KWIATKOWSKI, C., Use of sewage sludge in bioenergy production - A case study on the effects on sorghum biomass production, Europ. J. Agronomy, 69, 2015, 63-74, https://doi.org/10.1016/j.eja.2015.06.004. 